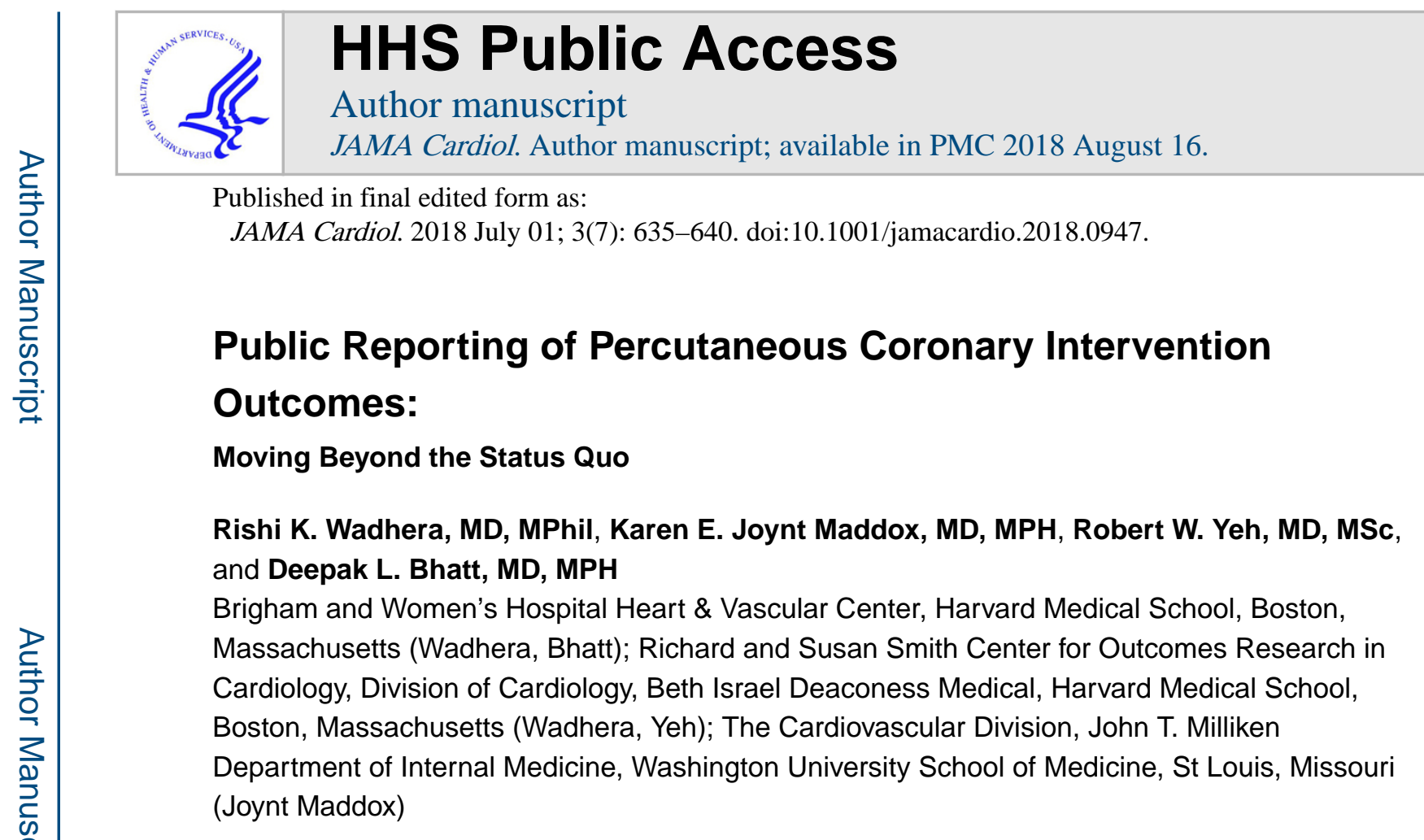

Abstract

IMPORTANCE-More than 20 years have passed since public reporting of percutaneous coronary intervention (PCI) outcomes first began in New York State, but reporting remains a polarizing issue.

OBSERVATIONS-Advocates of public reporting point to the strong incentive that public disclosure of outcomes data provides for institutions and clinicians to improve clinical care and to the importance of enabling patients to make informed choices about their care. Critics highlight the methodological challenges that impede fair and accurate assessments of care quality as well as reporting's unintended consequences. Public reporting of PCI outcomes has only been implemented in 5 states, but reporting efforts for multiple conditions and procedures are now proliferating nationally, propelled by the notion that transparency improves the quality of health care and fosters trust in health care institutions. Careful evaluation of the evidence to date for PCI in particular, however, suggests that enthusiasm for such efforts should be tempered.

Corresponding Author: Deepak L. Bhatt, MD, MPH, Brigham and Women's Hospital Heart \& Vascular Center, Harvard Medical School, 75 Francis St, Boston, MA 02115 (dlbhattmd@post.harvard.edu).

Conflict of Interest Disclosures: All authors have completed and submitted the ICMJE Form for Disclosure of Potential Conflicts of Interest. Dr Bhatt reported serving on the advisory boards of Cardax, Elsevier Practice Update Cardiology, Medscape Cardiology, and Regado Biosciences; being on the board of directors of Boston VA Research Institute and the Society of Cardiovascular Patient Care; serving as chair of the American Heart Association Quality Oversight Committee; serving on the data monitoring committees of the Cleveland Clinic, Duke Clinical Research Institute, Harvard Clinical Research Institute, Mayo Clinic, Mount Sinai School of Medicine, and Population Health Research Institute; receiving honoraria from the American College of Cardiology (vice-chair, ACC Accreditation Committee), Belvoir Publications, Duke Clinical Research Institute, Harvard Clinical Research Institute, HMP Communications, Journal of the American College of Cardiology, Population Health Research Institute, Slack Publications, Society of Cardiovascular Patient Care, and WebMD; being associated with Clinical Cardiology, NCDR (National Cardiovascular Data Registry) ACTION (Acute Coronary Treatment Intervention Outcomes Network) Registry Steering Committee (chair), and VA CART Research and Publications Committee (chair); receiving research funding from Abbott, Amarin, Amgen, AstraZeneca, Bristol-Myers Squibb, Chiesi, Eisai, Ethicon, Forest Laboratories, Ironwood, Ischemix, Lilly, Medtronic, Pfizer, Regeneron, Roche, Sanofi, and The Medicines Company; receiving royalties from Elsevier; being site co-investigator for Biotronik, Boston Scientific, St Jude Medical (now Abbott), and Svelte; serving as trustee of the American College of Cardiology; and conducting unfunded research with FlowCo, Merck, PLx Pharma, and Takeda. Dr Joynt Maddox reported doing intermittent contract work for the US Department of Health and Human Services. No other disclosures were reported. 
CONCLUSIONS AND RELEVANCE-Public reporting has not achieved its primary objectives. Policy makers should consider variations of reporting that might strengthen care quality, empower patients, and mitigate undesirable repercussions.

More than 20 years have passed since public reporting of percutaneous coronary intervention (PCI) outcomes began in New York State, but reporting remains a polarizing issue. Advocates of public reporting point to the strong incentive that public disclosure of outcomes data provides for institutions and clinicians to improve clinical care and to the importance of enabling patients to make informed choices about where and from whom to seek care. Critics highlight the methodological challenges that impede fair and accurate assessments of care quality as well as reporting's unintended consequences.

Public reporting of PCI outcomes has only been implemented in 5 states, but national efforts to report outcomes for multiple conditions and procedures are now gaining traction through media organizations and national societies. These initiatives have been propelled by the notion that transparency improves the quality of healthcare, empowers patients, and fosters trust in health care institutions. ${ }^{1,2}$ However, careful evaluation of the evidence to date for PCI in particular suggests that enthusiasm for such efforts should be tempered.

In this article, we argue that this current policy has not achieved its primary objectives. We review the advantages, challenges, and limitations of current public reporting initiatives for PCI. In addition, we discuss possible future variations of reporting - disease-based reporting, process measure and patient-centric reporting, and non public reporting (Figure) - that might strengthen care quality, empower patients, and mitigate undesirable repercussions.

\section{Current State of PCI Public Reporting Initiatives}

To evaluate how well public reporting initiatives have achieved their goals, the answers to 3 fundamental questions are necessary: (1) Has reporting improved physician behavior and patient outcomes? (2) Do public reports fairly and accurately reflect physician and institutional care quality? (3) Have patients used public reports in a way that meaningfully shapes their decision making?

\section{Physician Behavior and Patient Outcomes}

Public reporting has undoubtedly affected physician behavior, although not necessarily in a positive way. In Massachusetts, use of coronary angiograms and PCI for acute myocardial infarction (AMI) decreased considerably following the implementation of a public reporting program. ${ }^{3}$ In general, the likelihood of receiving PCI for AMI has been shown to be lower in states with reporting programs compared with states without. ${ }^{4}$ These patterns would be desirable if they definitively reflected a reduction in inappropriate or futile cases, but lower rates of PCI in states with reporting programs have been most pronounced among patientssuch as those with AMI complicated by cardiogenic shock-who may stand to gain the most from intervention. ${ }^{3-7}$ Furthermore, in a recent survey, most interventional cardiologists admitted to, at times, not performing high-risk but indicated PCIs because they were concerned that a bad outcome might negatively affect their publicly reported outcomes. ${ }^{8,9}$ 
This evidence of physician risk aversion suggests that transparency may impose a powerful incentive to avoid public shame, altering physicians' clinical decision making in a manner that can be ultimately harmful to patient care. ${ }^{10}$

It is not surprising then that reporting has not been associated with clear improvements in patient outcomes. An analysis of Medicare beneficiaries in Massachusetts found no difference in 30-day AMI mortality rates before and after the implementation of public reporting. The analysis, however, noted higher mortality rates among patients with STsegment elevation myocardial infarction (STEMI) in states with reporting programs compared with states without. ${ }^{3}$ A more recent study found substantially higher in-hospital AMI mortality rates in Massachusetts and New York compared with states without reporting programs; this difference appeared to be driven primarily by increased mortality among patients who did not receive PCI. ${ }^{4}$ Similarly, a propensity-adjusted analysis of patients with AMI and cardiogenic shock in New York, compared with states with-out reporting programs, showed that in-hospital mortality rates were nearly 2-fold higher among patients who did not undergo revascularization and were similar among those who did. ${ }^{5}$ In contrast, in states with reporting programs, patients who received PCI for both nonacute and acute indications were shown to have a substantially lower risk of death. However, the better outcomes noted in this procedure-based analysis likely reflect some degree of case selection.

${ }^{11}$ Collectively, the evidence to date suggests that public reporting impedes access to potentially life-saving interventions for the critically ill. ${ }^{3-5,8,9}$

\section{Fair and Accurate Assessment of Care Quality}

Most interventional cardiologists have expressed skepticism about the ability of publicly reported mortality rates to accurately measure care quality. ${ }^{8}$ Mortality reporting falls short as a stand-alone quality measure for a number of reasons. First, mortality may not truly reflect PCI quality but rather the totality of care provided by the care team across the clinical episode-from the nursing staff in the coronary care unit to the intern completing the discharge paperwork; attributing mortality to the PCI operator alone may be inappropriate. This reasoning is supported by a study that demonstrated a lack of association between procedural quality and post-PCI mortality, and it also explains why so few interventional cardiologists believe that reported mortality rates reflect physician quality. ${ }^{8,12}$ Second, because the incidence of mortality after PCI is low, measuring performance for centers or operators with low volumes is difficult. ${ }^{13,14}$

Beyond the limitations of using mortality as the sole metric of quality, challenges associated with risk adjustment may limit fair comparisons of performance. For instance, accounting for confounding is challenging because of variables that are unmeasured or difficult to quantify, such as acuity of patient presentation. ${ }^{13}$ High-risk clinical variables in high-risk patients are also underrepresented in samples used to construct risk models, which may result in models that do not fully account for infrequent but highly prognostic factors. ${ }^{15} \mathrm{In}$ addition, independent adjudication has shown that up-coding of comorbidities and other high-risk variables in PCI has occurred in states with reporting programs, and many interventional cardiologists believe that upcoding remains prevalent, which diminishes the accuracy of risk adjustment. ${ }^{9,16}$ Some combination of these factors may explain why a 
recent analysis by the National Cardiovascular Data Registry found unstable operator-level, risk-standardized PCI mortality rates from year to year. ${ }^{17}$

\section{Meaningful Use of Public Reports}

To engage patients and allow them to make informed decisions about their own care, public reporting initiatives use transparency to diminish asymmetric information between physicians and patients regarding physician care quality. Transparency is also intended to engender trust from the public at large, which is particularly important in an increasingly consumer-driven health care system.

However, there is no evidence that patients use public reports in a meaningful way. ${ }^{18,19}$ One analysis found that even when parents select a physician for their own children, factors such as acceptance of health insurance, office location, and word-of-mouth reputation are far more important than physician ratings. ${ }^{20}$ Furthermore, in an era in which narrow network and managed care insurance plans are rapidly growing, patients' ability to freely choose their physician is becoming more limited.

Remarkably, few patients who received PCI use these public reports, even in states with long-standing reporting programs. A recent survey of patients who underwent PCI in New York State found that only $5 \%$ had heard of the state's public reports and less than $3 \%$ had actually viewed them. ${ }^{8}$ This low awareness reflects that other factors likely matter much more when patients choose a physician for PCI and that, in the case of urgent PCI, patients have little say in who performs their procedure. Public reports also appear to have negligible association with physician referral patterns. ${ }^{18,19,21}$ The most rampant consumer of public reports appear to be media organizations, which are often keen to highlight institutions that achieve poor outcomes. ${ }^{22,23}$

\section{Future Public Reporting Initiatives}

Despite evidence that public reporting of PCI outcomes has not clearly improved care quality or empowered patients, reporting efforts are proliferating nationally. This growth is, in part, being driven by a broader movement to improve transparency in health care. Momentum, however, is not a reason to preserve a policy that fails to achieve its primary objectives and potentially results in harm. Concerted efforts have been made to enhance public reporting, such as iterative improvements of the risk-adjustment methodology, ${ }^{24}$ the exclusion from reports of patients with refractory cardiogenic shock, ${ }^{25-27}$ and calls by national societies-due to concerns regarding physicians' risk aversion - to exclude from reports patients who had a cardiac arrest outside of the hospital. ${ }^{28-30}$ However, these efforts alone have not adequately addressed the fundamental limitations of current reporting initiatives. Here, we discuss alternative approaches to reporting that might strengthen care quality and mitigate undesirable consequences.

\section{Disease-Based Reporting}

Because syndromes amenable to PCI encompass a spectrum of pathophysiological and clinical states, reporting mortality by disease subgroups, such as unstable angina, nonSTEMI, STEMI, and even AMI complicated by cardiogenic shock or arrest—irrespective of 
whether a patient is treated with medical therapy or revascularization-would provide a comprehensive assessment of care quality.

Disease-based reporting could address several shortcomings of current reporting efforts. First, it would eliminate the strong incentive that current PCI-centered reporting initiatives impose on physicians to avoid high-risk cases, and it would encourage the use of optimal therapy (medical therapy vs PCI) for each patient because institutions would be evaluated on the basis of disease outcomes and not procedure outcomes. ${ }^{31}$ Second, it would allow institutions to discern whether, for example, they perform better than expected for patients with non-STEMI but worse for patients with unstable angina. This targeted feedback would allow institutions to pursue more focused interventions to improve systems of care. Third, it would allow for more balanced comparisons of performance and diminish the reliance on risk adjustment. Fourth, it would facilitate transparency regarding the care delivered by the entire care team rather than by interventional physicians alone, and it would encourage collaborative, team-oriented approaches to improve care quality. Fifth, it would be simpler for patients to understand and could increase patients' use of public reports.

Past efforts to regionalize acute STEMI care could also provide a valuable opportunity to implement disease-based reporting for regional systems of care, even beyond reporting for physicians and hospitals. ${ }^{32,33}$ This effort would foster interinstitutional collaboration, likely discourage the selective transfer of critically ill patients (due to physicians' risk a version) from one institution to another, and encourage the appropriate transfer of patients with complex conditions that might need care at a tertiary care facility. The association between reporting regional care networks' outcomes and quality has not been well studied and would require careful evaluation. ${ }^{32}$

The Centers for Medicare and Medicaid Services has publicly reported hospital 30-day AMI mortality measures since $2007 .{ }^{34}$ These annually updated metrics are not only accessible to the public but also easy to understand as they use simple patient-oriented terms-such as "better than the national rate"- to convey institutional performance. ${ }^{34}$ In addition, these AMI mortality data are used to determine financial rewards or penalties for more than 3000 institutions participating in pay-for-performance initiatives. The Centers for Medicare and Medicaid Services might consider expanding this initiative by publicly reporting mortality rates for AMI disease subgroups and by coupling performance on these measures with other emerging value-based or alternative payment models (ie, bundled payments), which could create a powerful incentive to improve care quality and concomitantly address unintended consequences.

Another option is to develop state AMI registries for both data collection and quality improvement. An AMI registry with detailed clinical data would provide granular information on outcomes for AMI subtypes, allow for more accurate risk adjustment, and provide a comprehensive assessment of clinician or institutional performance. New York, for example, is already leading an effort to implement an AMI-specific registry. The use of AMI registries to publicly report outcomes could diminish clinicians' risk-aversive behavior and provide more accurate comparisons of care quality between institutions, though it is not clear to what extent—beyond what active quality-improvement initiatives achieve-these 
efforts would improve care quality in states without reporting programs. In the absence of such evidence, the question remains whether states and institutions should invest in the creation and maintenance of registries simply in the name of transparency.

\section{Process Measure and Patient-Centric Reporting}

A movement toward prioritizing outcome measures, such as mortality, has occurred in public reporting and value-based payment programs. Mortality associated with PCI is arguably the most important outcome to both patients and physicians, although it may not be the best or most accurate metric of the quality of PCI care delivered. Because numerous factors-often beyond the control of an interventional cardiologist—can influence mortality for urgent PCI, state reporting programs might consider using metrics that more precisely reflect how care is delivered.

Process-of-care measures, such as timely administration of aspirin or time to PCI for a highrisk non-STEMI, provide insight regarding aspects of care quality that are directly attributable to clinicians and systems of care. Such data would provide more specific, tangible feedback to institutions on where and how to enhance care delivery and facilitate interventions to improve quality. In addition, higher performance on process measure metrics is associated with lower AMI mortality. ${ }^{35}$ A precedent for publicly reporting process measures already exists; the Centers for Medicare and Medicaid Services does so for Medicare beneficiaries with AMI and often incorporates these measures into value-based payment programs. ${ }^{36}$ Process measures might be used together with mortality-which is generally accepted as the ultimate measurement of performance- to provide a more comprehensive assessment of the quality of care delivered.

For PCIs performed for nonurgent indications, such as stable angina, patient-reported outcomes may better reflect how clinical decision making has affected symptoms and quality of life. A validated tool, such as the Seattle Angina Questionnaire, ${ }^{37,38}$ could be incorporated into routine care for PCI, or even as a disease-based reporting approach, and would provide real-time feedback to physicians. ${ }^{39}$ The use of patient-reported outcomes has proliferated in other fields and has been associated with increased physician satisfaction, better patient care, and enhanced shared decision making, albeit with mixed workflowefficiency results. ${ }^{39,40}$ Another controversial approach is to report measures of patient experience. This approach would empower patients to decide if they are receiving highquality care and provide formative feedback to institutions about what patients value. ${ }^{41}$ Emphasizing the patient experience might give hospitals an incentive to focus on superficial aspects of care, but evidence suggests that patients tend to give higher ratings to hospitals that provide better-quality care. ${ }^{42}$ Given that the risk of mortality among patients who received nonacute PCI is so low that variation between physicians often reflects chance rather than true differences in care delivery, shifting to patient-reported measures would facilitate a more meaningful, patient-centric assessment of clinician care quality. ${ }^{13}$

\section{Nonpublic Reporting}

Nonpublic reporting of PCI outcomes is another viable alternative to current reporting efforts. A formal system of sharing outcome information among physicians and institutions 
within a state would promote accountability and enable peer-reviewed analyses and coaching to improve care quality. In addition, given that fear of public shame is likely what drives physicians to alter their clinical decision making, particularly concerning high-risk patients, and potentially compels them to upcode documentation, completely removing the "public" element of reporting might help address these behaviors. $8,9,31$ This change may have minimal implications for patient behavior given evidence that patients do not often read these reports. ${ }^{8}$ By facilitating peer-driven analyses of performance and quality improvement, nonpublic reporting among institutions might motivate the "positive" behavioral changes among clinicians that original reporting initiatives intended and might diminish the "negative" behaviors driven by fear of public or media embarrassment.

Michigan has successfully implemented Collaborative Quality Initiatives (CQI), a nonpublic reporting program that has improved PCI care quality among regional institutions. ${ }^{43}$

Through CQI, hospitals and physicians throughout the state share information regarding care quality and outcomes for PCI, which is collected and entered into a central registry. This information is used to ensure that institutions are achieving target process measures and complication rates and to help identify opportunities for quality improvement. Evidence to date demonstrates an association between CQI and better care quality and PCI outcomes. ${ }^{44}$ When compared with public reporting programs in New York, CQI is shown to be associated with lower levels of physician risk aversion. ${ }^{45}$ Expanding peer-driven, nonpublic reporting initiatives such as CQI to other states would provide an impetus for collaboration and diminish the unintended repercussions of current public reporting efforts. In states that already report PCI outcomes, a shift to nonpublic reporting might be accomplished with the infrastructure already in place for public reporting.

\section{Other Concerns}

Our proposed alternatives would address some of the limitations and ramifications of current reporting initiatives, but many questions remain beyond how best to reshape these programs. First, who should take on public reporting? The Centers for Medicare and Medicaid Services continues to report institutional performance on 30-day AMI mortality rates for Medicare beneficiaries. In addition, national societies and media organizations are expanding reporting initiatives. ${ }^{1,2,46}$ Will this explosion of public reporting improve patient awareness of and engagement with these data? Or will this influx of information simply overwhelm and confuse patients, further diluting one of the major aims of reporting - to inform and empower the consumer?

Second, who will ensure that public reports generated from multiple sources are methodologically sound and accurately reflect care quality, and should methodological transparency be mandated ${ }^{47}$ There is already evidence of hospitals being given discordant "grades" by different reporting agencies, which creates confusion for both institutions and patients. ${ }^{48}$ Interestingly, the Healthcare Association of New York State has pushed back on the confusion incited by multiple reporting agencies, creating its own "Report on Report Cards," which evaluates the performance of reporting agencies on a scale of 0 to 3 stars. ${ }^{49}$ 
Public reporting is evolving into a big business, and the data collected could be sold to regulatory agencies, insurance carriers, and other entities. Have we unintentionally pushed the growth of a business sector built on selling data, analytic, or consulting services, and will all of this improve patient care? In addition, few data on the costs of public reporting are available, particularly for PCI. It is clear, however, that beyond the costs of running a state reporting program, current PCI reporting initiatives impose a financial burden on physicians and institutions. At a time when great emphasis is placed on "bending the cost curve" in health care, we should ask ourselves whether public reporting is truly a high-value endeavor.

\section{Conclusions}

Public reporting of PCI outcomes began with the best of intentions-to motivate physicians and institutions, improve patient care, and enable patients to make informed decisions. Unfortunately, reporting has not improved outcomes, and patients rarely use this information. Advocates of public reporting might contend that these initiatives have improved clinical decision making and led to appropriate selection of patients for PCI, but little evidence exists to support these claims. Rather, there is stronger evidence regarding physician risk aversion and limited access to PCI among the critically ill.

As PCI reporting initiatives increase nationally, it is important to ask how a policy that has not proved advantageous for patients and has the potential to cause harm persisted for more than 2 decades. The likely answer is that public reporting's suggestion of "transparency" evokes a resoundingly positive sentiment - that we are cultivating trust in the medical system and being open and honest with patients, thus improving their healthcare experience. Today, we must shift from an idealism-based to an evidence-based public reporting policy. A good place for current state programs to start may be to move from procedure-based to disease-based reporting, which could preserve some of the transparency advantages of reporting while minimizing some of the unintended consequences. In addition, ending reporting initiatives - and instead focusing on the development and expansion of quality improvement programs - should be considered but may be politically unpalatable. No matter what consensus is reached regarding how to address public reporting of PCI outcomes, we must realize that it is time to move beyond the status quo.

\section{References}

1. Wei S, Pierce O, Allen M. Surgeon scorecard. ProPublica; https://projects.propublica.org/surgeons/. Updated July 15, 2015 [Accessed November 15, 2017]

2. Harder B, Comarow A. Hospital quality reporting by US News \& World Report. why, how, and what's ahead. JAMA. 2015; 313(19):1903-1904. [PubMed: 25988456]

3. Joynt KE, Blumenthal DM, Orav EJ, Resnic FS, Jha AK. Association of public reporting for percutaneous coronary intervention with utilization and outcomes among Medicare beneficiaries with acute myocardial infarction. JAMA. 2012; 308(14):1460-1468. [PubMed: 23047360]

4. Waldo SW, McCabe JM, O’Brien C, Kennedy KF, Joynt KE, Yeh RW. Association between public reporting of outcomes with procedural management and mortality for patients with acute myocardial infarction. J Am Coll Cardiol. 2015; 65(11):1119-1126. [PubMed: 25790884]

5. Apolito RA, Greenberg MA, Menegus MA, et al. Impact of the New York State Cardiac Surgery and Percutaneous Coronary Intervention Reporting System on the management of patients with acute 
myocardial infarction complicated by cardiogenic shock. Am Heart J. 2008; 155(2):267-273. [PubMed: 18215596]

6. Moscucci M, Eagle KA, Share D, et al. Public reporting and case selection for percutaneous coronary interventions: an analysis from two large multicenter percutaneous coronary intervention databases. J Am Coll Cardiol. 2005; 45(11):1759-1765. [PubMed: 15936602]

7. Wadhera RK, Anderson JD, Yeh RW. High-risk percutaneous coronary intervention in public reporting states: the evidence, exclusion of critically ill patients, and implications. Curr Heart Fail Rep. 2017; 14(6):514-518. [PubMed: 29101664]

8. Fernandez G, Narins CR, Bruckel J, Ayers B, Ling FS. Patient and physician perspectives on public reporting of mortality ratings for percutaneous coronary intervention in New York State. Circ Cardiovasc Qual Outcomes. 2017; 10(9):e003511. [PubMed: 28893831]

9. Blumenthal DM, Zhao Y, Shen C., et al. Public Reporting of PCI Outcomes and Provider Risk Aversion: The Results of a Survey of Interventional Cardiologists in Massachusetts and New York. Anaheim, CA: American Heart Association; 2017.

10. Feldman DN, Yeh RW. Public reporting of percutaneous coronary intervention mortality in New York State: are we helping our patients? Circ Cardiovasc Qual Outcomes. 2017; 10(9):e004027. [PubMed: 28893834]

11. Cavender MA, Joynt KE, Parzynski CS, et al. State mandated public reporting and outcomes of percutaneous coronary intervention in the United States. Am J Cardiol. 2015; 115(11):1494-1501. [PubMed: 25891991]

12. Resnic FS, Welt FG. The public health hazards of risk avoidance associated with public reporting of risk-adjusted outcomes in coronary intervention. J Am Coll Cardiol. 2009; 53(10):825-830. [PubMed: 19264236]

13. Weintraub WS, Garratt KN. Challenges in risk adjustment for hospital and provider outcomes assessment. Circulation. 2017; 135(4):317-319. [PubMed: 28115411]

14. Faridi K, Yeh RW. Should PCI outcomes be publically reported?. American College of Cardiology; http://www.acc.org/latest-in-cardiology/articles/2016/10/20/10/47/should-pci-outcomes-bepublically-reported. Published October 20, 2016 [Accessed November 23, 2017]

15. Gupta A, Yeh RW, Tamis-Holland JE, et al. Implications of public reporting of risk-adjusted mortality following percutaneous coronary intervention: misperceptions and potential consequences for high-risk patients including nonsurgical patients. JACC Cardiovasc Interv. 2016; 9(20):2077-2085. [PubMed: 27765301]

16. Barringhaus KG, Zelevinsky K, Lovett A, Normand SL, Ho KK. Impact of independent data adjudication on hospital-specific estimates of risk-adjusted mortality following percutaneous coronary interventions in Massachusetts. Circ Cardiovasc Qual Outcomes. 2011; 4(1):92-98. [PubMed: 21156880]

17. Doll JA, Dai D, Roe MT, et al. Assessment of operator variability in risk-standardized mortality following percutaneous coronary intervention: a report from the NCDR. JACC Cardiovasc Interv. 2017; 10(7):672-682. [PubMed: 28385404]

18. Faber M, Bosch M, Wollersheim H, Leatherman S, Grol R. Public reporting in health care: how do consumers use quality-of-care information? a systematic review. Med Care. 2009; 47(1):1-8. [PubMed: 19106724]

19. Ketelaar NA, Faber MJ, Flottorp S, Rygh LH, Deane KH, Eccles MP. Public release of performance data in changing the behaviour of healthcare consumers, professionals or organisations. Cochrane Database Syst Rev. 2011; (11):CD004538. [PubMed: 22071813]

20. University of Michigan C.S. Mott Children's Hospital. [Accessed October 24, 2017] National poll on children's health: how to select a child's doctor? parents prefer grapevine to online. https:// mottpoll.org/sites/default/files/documents/02182013_ChoosingADoctor.pdf. Published February 18,2013

21. Schneider EC, Epstein AM. Influence of cardiac-surgery performance reports on referral practices and access to care: a survey of cardiovascular specialists. N Engl J Med. 1996; 335(4):251-256. [PubMed: 8657242] 
22. Kowalczyk L. [Accessed March 30, 2018] Deaths lead to scrutiny of 2 heart units: state to watch MGH, Worcester hospital. Boston Globe. Feb 9, 2009. http://archive.boston.com/news/local/ massachusetts/articles/2009/02/09/deaths_lead_to_scrutiny_of_2_heart_units/

23. Sternberg S. USA Today. Feb 10, 2009 Premier hospital, high angioplasty death rate.

24. Resnic FS, Normand SL, Piemonte TC, et al. Improvement in mortality risk prediction after percutaneous coronary intervention through the addition of a "compassionate use" variable to the National Cardiovascular Data Registry CathPCI dataset: a study from the Massachusetts Angioplasty Registry. J Am Coll Cardiol. 2011; 57(8):904-911. [PubMed: 21329835]

25. Bangalore S, Guo Y, Xu J, et al. Rates of invasive management of cardiogenic shock in New York before and after exclusion from public reporting. JAMA Cardiol. 2016; 1(6):640-647. [PubMed: 27463590]

26. Hannan EL, Zhong Y, Cozzens K, et al. The impact of excluding shock patients on hospital and physician risk-adjusted mortality rates for percutaneous coronary interventions: the implications for public reporting. JACC Cardiovasc Interv. 2017; 10(3):224-231. [PubMed: 28183462]

27. McCabe JM, Waldo SW, Kennedy KF, Yeh RW. Treatment and outcomes of acute myocardial infarction complicated by shock after public reporting policy changes in New York. JAMA Cardiol. 2016; 1(6):648-654. [PubMed: 27463734]

28. Peberdy MA, Donnino MW, Callaway CW, et al. American Heart Association Emergency Cardiovascular Care Committee; Council on Cardiopulmonary, Critical Care, Perioperative and Resuscitation. Impact of percutaneous coronary intervention performance reporting on cardiac resuscitation centers: a scientific statement from the American Heart Association. Circulation. 2013; 128(7):762-773. [PubMed: 23857321]

29. Rab T, Wilson H. Interventional Council; Board of Governors. Public reporting of mortality after PCI in cardiac arrest and cardiogenic shock: an opinion from the interventional council and the board of governors of the American College of Cardiology. JACC Cardiovasc Interv. 2016; 9(5): 496-498. [PubMed: 26965939]

30. Klein LW, Harjai KJ, Resnic F, et al. 2016 Revision of the SCAI position statement on public reporting. Catheter Cardiovasc Interv. 2017; 89(2):269-279. [PubMed: 27755653]

31. Wadhera RK, Bhatt DL. Taking the "public" out of public reporting of percutaneous coronary intervention. JAMA. 2017; 318(15):1439-1440. [PubMed: 28973584]

32. Pottenger BC, Diercks DB, Bhatt DL. Regionalization of care for ST-segment elevation myocardial infarction: is it too soon? Ann Emerg Med. 2008; 52(6):677-685. [PubMed: 18755524]

33. Ting HH, Rihal CS, Gersh BJ, et al. Regional systems of care to optimize timeliness of reperfusion therapy for ST-elevation myocardial infarction: the Mayo Clinic STEMI Protocol. Circulation. 2007; 116(7):729-736. [PubMed: 17673456]

34. Data.Medicare.gov. [Accessed December 20, 2017] Complications and deaths-hospital. https:// data.medicare.gov/Hospital-Compare/Complications-and-Deaths-Hospital/ynj2-r877/data

35. Jha AK, Orav EJ, Li Z, Epstein AM. The inverse relationship between mortality rates and performance in the Hospital Quality Alliance measures. Health Aff (Millwood). 2007; 26(4):11041110. [PubMed: 17630453]

36. Medicare.gov. Measures and current data collection periods. Centers for Medicare \& Medicaid Services; Hospital Compare. https://www.medicare.gov/hospitalcompare/Data/Data-Updated.html [Accessed December 3, 2017]

37. Chan PS, Jones PG, Arnold SA, Spertus JA. Development and validation of a short version of the Seattle Angina Questionnaire. Circ Cardiovasc Qual Outcomes. 2014; 7(5):640-647. [PubMed: 25185249]

38. Spertus JA, Winder JA, Dewhurst TA, et al. Development and evaluation of the Seattle Angina Questionnaire: a new functional status measure for coronary artery disease. J Am Coll Cardiol. 1995; 25(2):333-341. [PubMed: 7829785]

39. Rotenstein LS, Huckman RS, Wagle NW. Making patients and doctors happier-the potential of patient-reported outcomes. N Engl J Med. 2017; 377(14):1309-1312. [PubMed: 28976860]

40. Basch E. Patient-reported outcomes-harnessing patients' voices to improve clinical care. N Engl J Med. 2017; 376(2):105-108. [PubMed: 28076708]

41. Jha AK. Payment power to the patients. JAMA. 2017; 318(1):18-19. [PubMed: 28672304] 
42. Isaac T, Zaslavsky AM, Cleary PD, Landon BE. The relationship between patients' perception of care and measures of hospital quality and safety. Health Serv Res. 2010; 45(4):1024-1040. [PubMed: 20528990]

43. Blue Cross Blue Shield Blue Care Network of Michigan. [Accessed December 10, 2017] The Blue Cross and Blue Shield of Michigan Percutaneous Coronary Interventions Collaborative (BMC2 PCI). https://bmc2.org/pci-overview

44. Moscucci M, Rogers EK, Montoye C, et al. Association of a continuous quality improvement initiative with practice and outcome variations of contemporary percutaneous coronary interventions. Circulation. 2006; 113(6):814-822. [PubMed: 16461821]

45. Boyden TF, Joynt KE, McCoy L, et al. Collaborative quality improvement vs public reporting for percutaneous coronary intervention: a comparison of percutaneous coronary intervention in New York vs Michigan. Am Heart J. 2015; 170(6):1227-1233. [PubMed: 26678645]

46. [Accessed May 17, 2017] National Cardiovascular Data Registry. Public reporting. https:// www.ncdr.com/WebNCDR/home/public-reporting

47. Bilyk J. [Accessed December 21, 2017] Saint Anthony Hospital sues ratings agency Leapfrog, said knowingly used incorrect info to lower grade. https://cookcountyrecord.com/stories/511258985-

saint-anthony-hospital-sues-ratings-agency-leapfrog-said-knowingly-used-incorrect-info-to-lowergrade. Published November 3, 2017

48. Rice S. [Accessed March 30, 2018] Experts question hospital raters' methods. Modern Healthcare. http://www.modernhealthcare.com/article/20140531/MAGAZINE/305319980\#. Published May 31, 2014

49. HANYS Quality Institute. [Accessed December 21, 2017] HANY's report on report cards: understanding publicly reported hospital quality measures. https://www.hanys.org/quality/data/ report_cards/2013/docs/2013_hanys_report_card_book.pdf. Published October 2013 


$\begin{aligned} & \text { Goals of public reporting } \\ & \text { Motivate physicians and } \\ & \text { institutions to improve } \\ & \text { care quality }\end{aligned}$
$\begin{aligned} & \text { Mothod } \\ & \text { Risk adjustment }\end{aligned}$
$\begin{aligned} & \text { Physician } \\ & \text { Risk aversion }\end{aligned}$

Figure.

Goals, Challenges, and Potential Solutions for Current Public Reporting of Percutaneous Coronary Intervention Outcomes 